\title{
Gender and Reproductive Outcomes: The Effects of a Radio Serial Drama in Northern Nigeria
}

\author{
Fatou Jah, Scott Connolly, Kriss Barker, and William Ryerson \\ Population Media Center, Shelburne, VT 05482, USA \\ Correspondence should be addressed to Fatou Jah; fjah@populationmedia.org
}

Received 30 April 2014; Revised 22 July 2014; Accepted 23 July 2014; Published 14 September 2014

Academic Editor: Kathryn Kost

Copyright ( 2014 Fatou Jah et al. This is an open access article distributed under the Creative Commons Attribution License, which permits unrestricted use, distribution, and reproduction in any medium, provided the original work is properly cited.

\begin{abstract}
A large body of evidence has documented the effectiveness of mass-media communication programs in increasing family planning use and changing reproductive behavior. But the potential impact of these programs on the mediating role of gender norms has not been systematically assessed in Nigeria. Regionally representative cross-sectional end line data collected for the evaluation of a long-running entertainment-education radio serial drama program aired in northern Nigeria are examined for program effects on both reproductive and gender outcomes as well as the relative effect of gender on reproductive outcomes. The drama was popular, with $70 \%$ of the sample listening weekly. Results show that the drama positively impacted both sets of outcomes especially the reproductive outcomes. Results further indicate a strong relative effect of gender on reproductive issues.
\end{abstract}

\section{Introduction}

The effectiveness of mass-media entertainment-education programs in increasing contraceptive use, spousal reproductive decision-making including family size and fertility regulation, and positive reproductive behavior is well documented [1-18].

However, relatively few of these programs have evaluated the effect of program exposure on various dimensions of gender that mediate the link between program strategies and reproductive processes, especially in sub-Saharan Africa. There are several reasons for this gap. Program components that specifically address how gender norms have been impacted are relatively nascent in Africa, having gained attention in the reproductive health (RH) sphere only in the past decade largely due to the emphasis placed on the role of gender issues in RH by the 1994 International Conference on Population and Development [19].

Program activities may unintentionally influence gender norms, simply because these sociocultural factors are inextricably linked to all aspects of reproductive, social, and economic relations. Family planning (FP) and RH programs can have an empowering effect on girls and women.
Averting unintended pregnancies through FP fosters girls' continued schooling and women's engagement in profitable employment and reduces maternal and child morbidity and mortality. At the same time, the ability of women and girls to enjoy these empowering and health benefits of FP is constrained by the overarching sociocultural milieu, which is rooted in gender inequality $[20,21]$. Husbands and partners who have vested interest in having many children are the usual gatekeepers of reproductive decision-making, limiting women's reproductive agency [22].

Yet, most evaluations have focused their attention on assessing program effects on reproductive outcomes but not specifically on gender outcomes (see $[4-6,8,10,12,14$, $16,23])$. Substantive evaluations of these mediating gender outcomes using African data are even more scant because of unavailability of the kind of systematic gender disaggregated data that permit such evaluations.

The goal of this paper is to help fill the existing gap in simultaneous assessments of program effects on changes in both reproductive outcomes and gender outcomes employing African data and focusing on both males and females. It takes advantage of unique regionally representative cross-sectional survey data assessing the effects of a long-running radio 
serial drama aired in northern Nigeria to address problems of maternal and child mortality and morbidity arising from low contraceptive use. These data are unique in the fact that they contain a rich set of measures on both reproductive and gender outcomes, permitting a simultaneous assessment of both sets of outcomes. The study attempts to answer three research questions.

(i) What is the effect of the drama on FP and $\mathrm{RH}$ attitudes, intentions, and behaviors?

(ii) What is the effect of the drama on gender norms and attitudes that are presumed to mediate $\mathrm{RH}$ and FP attitudes, intentions, and behavior?

(iii) What is the relative effect of gender on each of the $\mathrm{RH}$ outcomes?

The study's focus on sub-Saharan Africa is timely. Fertility desires and intentions of both marital partners are important predictors of a couple's fertility [3]. Evaluating the effects of a $\mathrm{RH}$ intervention in northern Nigeria (a region where reproductive indicators have been persistently dismal) with an additional focus on gender norms and attitudes provides an avenue for improving program effectiveness and informing future programs. On a continental scale, Africa remains the only world region where fertility is persistently high; it trails behind other developing regions in reaching the Millennium Development Goals (MDGs) [24], the international blueprint for development in the new millennium. Although several countries in the region have initiated fertility transition, recent reports indicate unanticipated stalls in the transition in some of these countries during the latter part of 1990 and early 2000s [25-27]. As we get close to 2015, the target date for the attainment of the MDGs, focus on the RH, and gender inequality nexus has never been more imperative, as has been reiterated by scholars [28].

\section{Context}

With a population estimated at over 160 million, Nigeria ranks as the largest country in Africa in terms of population size. An annual growth rate of $2.5 \%$ that shows no sign of abating makes Nigeria a very youthful country with $45 \%$ of the population aged below 15 [29]. This high growth rate is blamed on low contraceptive prevalence and high fertility. Between 2003 and 2008 modern contraceptive use by married women increased by only 2 percentage points, from $8 \%$ to $10 \%$ [30]. About 1 in 5 currently married Nigerian women (21\%) intend to use FP in the future [30]. Reported reasons for future nonuse include religious, spousal, or women's own opposition to FP and the desire for large families. Lack of contraceptive services or cost was reported by just $0.2 \%$ of currently married Nigerians as barriers to future use [30]. Of all births in Nigeria, $87 \%$ were wanted at the time; $7 \%$ were wanted later; and $4 \%$ were unwanted [30]. Studies conducted in the country have also cited "perceived lack of need for contraception and fear of side effects" as reasons for nonuse $[30,31]$.
Total fertility rate (i.e., the average number of children borne by women) in 2008 is 5.7 children, unchanged since 2003 [30]. Ideal family size for Nigerian women is 7 children (9 children for men), making actual fertility lower than desired fertility [30]. Experts agree that a 3-year interval between deliveries is ideal for maternal and child health $(\mathrm{MCH})$ and that child spacing can contribute to both a reduction in fertility rates of a country [30] and infant mortality [32]. But $24 \%$ of Nigerian women have birth intervals shorter than two years [30], leaving infant mortality unacceptably high, at 89 deaths per 1,000 live births [29].

Maternal mortality, estimated at 545 maternal deaths per 100,000 live births [30], is high as is maternal morbidity. Prolonged obstructed labor is common and the incidence of vesicovaginal fistula (VVF) is 2.11 per 1000 cases annually [33]. According to recent estimates, only 1 in 3 women in Nigeria receive skilled assisted childbirth, resulting in $64 \%$ of births considered as high risk [30]. Life expectancy is just 52 years [30], impacted indirectly by HIV/AIDS. The HIV prevalence rate in 2009 was $3.6 \%$ in the adult population, making Nigeria the second country with the largest number of people living with HIV in Africa, after South Africa [29].

Health and socioeconomic indicators are even more dismal in northern Nigeria. In addition to closely spaced births and pregnancies among older women, teenage pregnancies (ages 15-19) contribute to high-risk births in this region of the country. While, nationally, teenage childbearing is $23 \%$, the rate is the highest in northern Nigeria, at about $45 \%$ [30]. Teenage childbearing and its associated problems of obstructed labor in the north result in high incidence of maternal mortality and morbidity and bowel and bladder incapacitating vesicovaginal fistula (VVF), with the latter linked to considerable stigma for afflicted women [34]. Early onset of childbearing stems from early marriage as discussed below.

Childhood marriage of girls in northern Nigeria remains the highest in the country, contributing to many social and health problems. The latest available figures [30] indicate that $20 \%$ of women are married by age 15 . But there are large regional differences, with the mean marriage age being over 7 years lower in the northwest (15.2 years) than in the southeast (22.8 years) regions. Further, based on the NPC and ICF Macro report [30] the median age at first marriage was 18.3 years for women aged 25-49, but 26 years for men in the same age range. This highlights substantial age gaps between spouses, an important correlate of gender asymmetries in marriage in the area of reproductive decision-making. One in 3 married women have cowives in Nigeria, but the figure is highest in the northeast region (43\%). This high prevalence of polygyny in northeast Nigeria, a phenomenon closely linked to wide spousal age gaps, further highlights gender inequalities within marriage. Nationally, the average woman desires 6 children, already high compared to most subSaharan African countries [35]. But the level is even higher in Nigeria's northeast where women, on average, want 8.1 children [30]. This greater desire for large families by women in the northeast is reflected in married women's relatively lower use of modern contraceptives (3\%) compared to their southwestern peers (21\%). 
Discussion of sex is traditionally a very private and sensitive issue due to cultural and religious reasons [31]. Such sensitivity, combined with a preference for large families, has made family planning initiatives in northern Nigeria challenging. Despite these sociocultural barriers, FP providers have found that discussion of fertility and FP with a spouse or partner has a strong positive association with contraceptive use $[22,36,37]$. Furthermore, in Islamic cultures, birth/child spacing for 2-3 years has gained widespread popularity because it is aligned with religious values promoted by the Koran and by many religious leaders as a means to promote maternal health [32].

\section{Gender and Reproduction: A Framework}

This study is conceptualized on the well-recognized connection between reproductive outcomes and various dimensions of gender recognized in the sociodemographic literature [19-21, 38-40]. These various dimensions of gender are reflected in women's socioeconomic position as determined by education and employment, age at marriage, decisions around marriage, marriage structure such as polygyny, spousal communication about pregnancy timing and family size, contraceptive behavior, and participation in household decision-making.

To take advantage of their education, educated women engage in paid employment, adopt small family norms, use contraception, and have lower fertility compared with their noneducated counterparts [38, 41-44]. Educated women also enjoy better RH and have healthier children because they engage in positive health care behaviors [39, 45, 46]. In this sense, education becomes an engine of socioeconomic mobility, which leads to greater reproductive agency. The education/fertility association is premised on education's role as a source of knowledge and information and in turn a transformer of attitudes. Women with formal education tend to question gender norms and existing power structures [42]. But the nature of this relationship is quite complex. Beyond being indirect, the education fertility relationship is further conditioned by the gender/marriage nexus, as has been attested in the demographic literature [28].

Women's delayed age at marriage stemming from prolonged schooling and employment has been hypothesized to lead to greater autonomy in their marriage decisions and an increase in consensual unions/cohabitation [44]. Such heightened autonomy is expected to translate into women's greater control of their fertility and reproductive behavior. On the other hand, polygyny, especially when coupled with large spousal age gaps, has been linked to gender inequality within marriage and less spousal communication about reproductive preferences, intentions, and behavior [36, 47]. Women's participation in household decision-making and control over their earnings are viewed as a source of empowerment and more equitable gender relations in marriage. However, this leverage within marriage for women has been qualified in the literature. Eloundou-Enyegue and Calves [48] find that, in Cameroon, women's marital leverage holds only where women are both equally or more educated than their husbands and are engaged in paid employment.
Related to Basu's [28] deemphasis on individual education as an empowering factor in wives' fertility, the significance of the prevailing gender context in conditioning reproductive processes and behavior has gained recognition in the gender and reproductive behavior literature. In a study of five ethnic groups in Nigeria, Kritz et al. [20] find that demand for children is the highest among two ethnic groups: the Hausa in northern Nigeria and the Kanuri in northeastern Nigeria relative to the Ibo, Ijaw, and Yoroba residing in other regions of the country. Importantly, the connection between ethnicity and reproductive behavior is influenced by the larger gender equity environment. Kritz and her colleagues [20] find asymmetric gender relations to be higher among the Hausa and Kanuri in Nigeria's north than the Ibo, Ijaw, and Yoroba in the southern and eastern regions of the country. Similarly, Mason and Smith [21] observe greater agreement between spouses over FP and reproductive intentions in gender contexts that are equitable than in very asymmetric gender contexts.

The conceptual framework presented above suggests that interventions should be designed to promote positive behavioral changes and gender attitudes in reproductive decisionmaking. To foster appreciation among northern Nigerians of the benefits of FP and equitable spousal RH decisionmaking, Population Media Center (PMC) produced and broadcast a long-running 208-episode radio serial drama, Ruwan Dare. The drama was broadcast in the Hausa language in Kano, Kaduna, Katsina, and Sokoto states from July 2007 to June 2009. The objectives of the drama program were to promote small family size norms; effective FP and birth spacing; delayed marriage and avoidance of obstructed labor and fistula; and gender equity. The government of Nigeria is signatory to international conventions promoting FP and reproductive wellbeing, including the 1994 ICPD program of action [19] and the MDGs [24], and the United Nations Population Fund (UNFPA) is active in the country to help the government achieve these international commitments. The drama was designed in tandem with Nigeria's institutional and policy mandates to enhance FP/RH through 4 behavioral change communication programs [49].

Ruwan Dare, which means "Midnight Rain" or "Midnight Dew" in Hausa, represents a metaphor for the intimate late night couple discussions surrounding FP and their lives in general [50]. This metaphoric conceptualization embodies positive, negative, and transitional (i.e., neutral) characters in the drama's storylines that gradually model how to discuss sensitive issues such as birth spacing, contraception, family size, and their gender dimensions and whether to seek maternity care to avoid obstructed labor and fistula. The drama sought to modify attitudes toward $\mathrm{FP} / \mathrm{RH}$ and gender issues through the respective stories of Azumi and Bawa.

Azumi's Story. Azumi, Lawai's first wife, is pregnant with her second child shortly after having given birth to a baby son. She is very ill during this second pregnancy, and the health worker says that if they do not give Azumi's body time to rest after this pregnancy, she will die. As Azumi recovers, she and Lawai decide to use FP to space their children. Lawai decides to get another wife because he wants to let Azumi rest. Azumi 
hears her parents' disapproval of her use of contraception and convinces Lawai to allow her to have another baby, but she almost dies during the pregnancy. Because of jealousy and greed, Lawai's second wife, Asibi, wants as many children as possible with Lawai and has several closely spaced births. Asibi becomes pregnant again, goes into a difficult labour, and dies during delivery. Asibi's death finally convinces Azumi that she should not get pregnant again so soon and to resume using FP.

Bawa's Story. Bawa and his wife have three daughters and live together happily. However, his mother (Kulu) is not content, because Bawa does not have a son. When Kulu moves in with him, she berates Bawa's wife and beats the childrenmaking life miserable for Bawa. Kulu becomes blind, and one of Bawa's daughters, little Kulu, is tasked with supervising her in town. She saves her grandmother from being hit by a car, but her grandmother blames her, saying that girls are stupid and should not be given responsibility and insists on hiring a boy to lead her. Bawa agrees, but the boy abandons the old woman when he sees his friends. Luckily little Kulu is across the street as she blindly steps in front of a speeding car. She saves her grandmother's life again, and the relieved person driving the car, a senator, rewards her with a scholarship for school. Bawa realizes the value of his wife and daughters and regrets having always listened to his mother.

\section{Broadcast Setting and Medium}

The northern states of Kaduna, Kano, Katsina, and Sokoto were identified as the target region for broadcast because they present the greatest need for a FP and reproductive behavior intervention. These northern states also house the highest rates of maternal mortality and VVF, nationally. The above proposed gendered framework is even more apt in the context of northern Nigeria relative to the remaining regions of the country as well as other countries in the subregion. In a sociocultural environment, where Hausa tradition is overlaid with Muslim ideology, Shariah Law, and the practice of seclusion for women, it becomes clear why reproductive and gender outcomes are less favorable than in the rest of the country or elsewhere in the continent. Accordingly, women and men play very different roles and enjoy different levels of authority in Hausa land compared to other regions [51]. Hausa is the dominant language and Islam the primary religion in the region. Radio is the optimal channel for FP messages for several reasons. It is the most widely consumed media in Nigeria, and almost 3 in 4 (74\%) households in Nigeria own a radio [30]. Further, it has the widest reach across the country and is more accessible and affordable than print or television. Among 15-59-year-old men and women, $60 \%$ and $40 \%$ have heard FP messages on the radio, respectively [30].

\section{Methodology}

5.1. Data Collection. To evaluate the program, a pretest, posttest research design was employed. In April 2007 and prior to broadcast, a regionally representative baseline crosssectional survey was conducted to collect benchmark data on all programmatic indicators and sociodemographic factors in the broadcast area of Kaduna, Kano, Katsina, and Sokoto states. Within each state, multistage stratified sampling was utilized for the sampling frame. In each state five urban locations and five rural locations were randomly chosen to ensure wide representation. Each local government area (LGA) of a state formed a cluster from which 200 households were randomly selected.

Face-to-face interviews were conducted with reproductive age women (15-49) and men (15-59) using household, women's and men's schedules, with questions mirroring those in the 2003 Nigeria Demographic and Health Surveys (DHS). Aligned with the program indicators, a wide range of themes were covered under the following modules: (1) sociodemographic characteristics, (2) media access, (3) marriage, (4) reproduction and fertility preferences and spousal communication about FP, (5) contraception, (6) sexual activity, HIV/AIDS, and other sexually transmitted infections, and (7) work and gender norms. Summative data were collected through an end line survey in July 2009, shortly after broadcast of the last drama episode. For analytical comparability, the same survey design and instrument used in the baseline were repeated in the end line. To assess listenership to the drama, an exposure module that measured listenership, character recall, and opinions about the drama was added to the end line instrument.

To improve data quality, enumerators and supervisors were trained on the protocol for implementing the survey prior to the fieldwork. Training stressed the need to pay attention to courteousness, confidentiality, sensitivities, culture, religion, and values of respondents. Female enumerators interviewed female respondents and male enumerators interviewed male respondents. A total of 793 respondents were drawn for the end line sample of which 671 completed the survey, translating in a response rate of $85 \%$.

5.2. Indicators. This study analyzes two sets of outcomes. Consistent with the goals of the project, Ruwan Dare, the first set of outcomes focuses on four aspects of FP/RH: (1) knowledge ("do you know a place where you can obtain a method of FP?"; "can people reduce their chances of getting the AIDS virus by using a condom every time they have sex?"); (2) attitudes ("is using contraception against the will of Allah/God?"; "couples should space their children at least 2.5 to 3 years apart"; "can becoming pregnant every year put the mother at risk?"; "people should plan how many children they will have"; "would you say that you approve or disapprove of couples using a family planning method to avoid getting pregnant?"; "what age do you think is most appropriate for a female to start bearing children?"; "would access to contraceptives encourage infidelity?"); (3) intentions ("would like to have no more children"; "do you think you will use a contraceptive method to delay or avoid pregnancy at any time in the future?"); and (4) behavior ("are you currently doing something or using any method of family planning to delay or avoid getting pregnant?"; "in the last 3 months have you 
discussed the practice of family planning with your family, friends, or neighbors?").

The analyses also examine the effect of the drama on a second set of outcomes, gender norms as they relate to reproductive issues and focus on three broad indicators of gender. The first is attitudes and behaviors related to normative beliefs and gender equality, including "what do you consider to be the ideal marriage age for a female?"; "discussed FP with spouse/partner in the last 3 months"; "couples should share responsibility for making decisions about family size"; "girls should be encouraged to continue their education to high levels"; "do you think that your husband/partner approves or disapproves of couples using a contraceptive method to avoid pregnancy?"; "who had the final say in the decision that you would get married to or live with your (first) husband/partner?"; "women should not be allowed to express their opinion on important family matters"; "a woman should be free to ask her husband to use a condom"; "a woman's value is judged by marriage before her first menses and by the number of children she has"; and "a man is never sterile but a woman can be." Scholars have argued that women's involvement in household financial issues and decision-making is a key component of women's empowerment [52]. Thus the second set of gender outcomes relates to attitudes surrounding women's economic empowerment such as "who in your family usually has the final say on making large household purchases?" and "who mainly decides how the money you earn will be used?"

The third set of gender outcomes focuses on attitudes related to domestic violence. The questions pertain to agreement with the following statements: "do you think a wife is justified in refusing to have sex with her husband if she knows he has a sexually transmitted infection?"; "do you think a wife is justified in refusing to have sex with her husband if she is tired or not in the mood?"; and "do you think a wife is justified in refusing to have sex with her husband if she knows he had sex with women other than his wives?" The study also asks about agreement over the following statements: "is a husband justified in hitting his wife if she goes out without telling him?"; "is a husband justified in hitting or beating his wife if she argues with him?"; "is a husband justified in hitting or beating his wife if she burns the food?"; and "is a husband justified in hitting or beating his wife if food is not cooked on time?" Although past studies [46] have created indices from these various gender measures for analyses, this study finds that different gender outcomes influence different RH outcomes as evidenced in the Section 6, and computing indices would have disguised these varying effects.

The independent variable considered in the study is an exposure variable that compares listeners to nonlisteners on key program indicators. Listenership is measured by a series of questions. Respondents were asked if they had "heard of the drama Ruwan Dare." Those who answered "yes" were asked if they had listened to " 1 or more episodes" of the drama. If they indicated "yes", they were further asked "how many episodes have you listened to each week?", with 3 as the maximum amount. Regular listeners were identified as having listened to 1 or more episodes per week; those who have not heard about or listened to the drama with less frequency were considered as nonlisteners.

Control variables are drawn from respondents' social and demographic characteristics. These include seven correlates: age, sex, marital status, educational attainment, ethnicity, state of residence, and urban/rural residence. The selection of these control variables is premised on large differentials in both the reproductive and gender outcomes by age, sex, ethnicity, marital status, education, rural versus urban residence, and state of residence in Nigeria, particularly in the northern parts of the country [30].

5.3. Analysis. This study examined the end line data that provide information on exposure to the drama. To answer the study's three research questions, the investigation was organized in three stages. In stage 1, we modeled the effect of exposure to the drama on the gender outcomes and, in stage 2, we modeled the effect of drama exposure on the FP/RH outcomes. In the final stage, to quantify the relative effect of gender on the FP/RH outcomes, we introduced measures of the gender outcomes as predictors in the models estimated in stage 2, essentially estimating the mediating effect of gender on the FP/RH outcomes. The equations associated with the three questions are given below.

Stage 1 Equation

$$
\log \frac{Y}{(1-Y)}=\beta_{0}+\beta_{l} L+\beta_{c} C+\varepsilon .
$$

$\log Y /(1-Y)$ is the log odds of the respective gender outcome being examined; $L$ measures the effect of drama exposure; $C$ is a matrix of the correlates; $\varepsilon$ is the error term; the $\beta$ s are the regression coefficients for the corresponding outcomes and correlates; $\beta_{0}$ is the constant.

Stage 2 Equation

$$
\log \frac{Y}{(1-Y)}=\beta_{0}+\beta_{l} L+\beta_{c} C+\varepsilon .
$$

$\log Y /(1-Y)$ is the log odds of the particular FP/RH outcome being examined; $L$ measures the effect of drama exposure; $C$ is a matrix of the correlates; $\varepsilon$ is the error term; the $\beta$ s are the regression coefficients for the corresponding outcomes and correlates; $\beta_{0}$ is the constant.

Stage 3 Equation

$$
\log \frac{Y}{(1-Y)}=\beta_{0}+\beta_{l} L+\beta_{c} C+\beta_{g} G+\varepsilon .
$$

$\log Y /(1-Y)$ is the log odds of the particular FP/RH outcome being examined; $L$ measures the effect of drama exposure; $C$ is a matrix of the correlates; $G$ is a matrix of the gender outcomes employed as predictors in these models; $\varepsilon$ is the error term; the $\beta \mathrm{s}$ are the regression coefficients for the corresponding outcomes and correlates; $\beta_{0}$ is the constant.

To assess the success of the drama, differences between listeners and nonlisteners on the outcomes were analyzed using statistical techniques that included chi-square and 
logistic regression in SPSS Version 21 (SPSS IBM). Each measure of reproductive and gender outcome was regressed on the listenership measure (our main predictor). In each of the three stages above, the models estimated both bivariate (without adjusting for any correlates) and multivariate (adjusted for the correlates) effects. Thus, the bivariate models estimate the gross effects of the drama while the multivariate models estimate net drama effects. Further, in the multivariate models, the measures for the correlates are serially incorporated. This allows us to detect the variable responsible for any critical change in the predictor. Given that logistic regression was used, all the outcome and control (except education which had several categories) variables were dichotomized.

\section{Results}

Table 1 shows the summary statistics of key variables used in the study. Results indicate that 793 respondents were successfully interviewed throughout the four states, of which 649 had heard about the drama. Of those who had heard of the drama, $70 \%$ regularly listened to Ruwan Dare at least once a week. Notwithstanding, considerable missing values due to nonresponse were observed for this exposure variable. The concern of nonresponse was more common with males, the married, urban residents, in Sokoto and Kaduna compared with Kano and Katsina, and among those whose ethnicity is Hausa. Further, there are differences across background characteristics in listenership. More females (57\%) followed the drama. Similarly, listenership was significantly greater among married/cohabiting individuals and among those whose first language is Hausa. Those with secondary education or higher and rural residents listened to the drama slightly more than those with less education and urban residents. However, Table 1 reveals no significant differences in background characteristics except along marital lines and first language. The remaining sections present the logistic regression results presented as odds ratios (bivariate estimates) and adjusted odds ratios (multivariate estimates), with significance and confidence levels set at 95\%.

6.1. Bivariate and Net Effects. This section presents the results of the evaluation of the effect of the drama on both the gender and reproductive outcomes at the bivariate and multivariate levels, with interpretations based mainly on the multivariate estimates.

6.1.1. Knowledge. Table 2 indicates that exposure to the drama had a positive association with knowledge about RH. Multivariate comparison of listeners and nonlisteners reveals that the odds of knowing a FP source were 1.9 times greater for listeners compared with nonlisteners. Similarly, the odds of listeners citing consistent use of condoms as a method of preventing HIV/AIDS were 1.8 times greater for listeners than nonlisteners. Interestingly, the bivariate effects on both outcomes were nonsignificant but the effect on knowledge of a FP source was rendered significant when the variable "state" was controlled for while knowledge of condoms as an HIV/AIDS prevention methods turned significant when education was adjusted for. These results suggest that failure to control for correlates would have yielded very different interpretations.

6.1.2. Attitudes. The odds of disagreeing with the statement that "using contraceptives is against the will of Allah" were 1.9 times greater for listeners than nonlisteners. Closely spaced births have an adverse effect on maternal and child health, posing greater risks for VVF. Respondents were asked "can becoming pregnant every year put the mother at risk?" The odds of listeners compared with nonlisteners agreeing with the statement were 1.9 times greater. Like the knowledge outcomes, the bivariate effects of the drama on these two attitudinal outcomes were nonsignificant and only turned significant with the introduction of the state variable in the model. Change in attitude toward birth spacing was also evaluated. Results show that the odds of listeners agreeing with the statement "couples should space children 2.5 to 3 years apart" were 2.9 times greater than those of nonlisteners.

Similar to the effect of the drama on the link between frequent pregnancies and maternal health, a positive change in attitude was observed for two other indicators: "people should plan how many children to have" and "would you say that you approve or disapprove of couples using a FP method to avoid getting pregnant?" Multivariate comparisons on both indicators suggest program effects: the respective odds were 2.6 and 1.8 times greater for listeners than for nonlisteners. Program effects on the last two attitudinal outcomes examined, disagreement with the notion that access to FP is associated with infidelity and the ideal age for the onset of childbearing, were nil in the sense that no significant differences between listeners and nonlisteners were observed, whether examined by chi-square statistics or multivariate analysis.

6.1.3. Intentions. Table 2 also gives the findings on the two indicators of reproductive intentions that were evaluated: "would like to have no more children" and "do you think you will use a contraceptive method to delay or avoid pregnancy at any time in the future?" On both outcomes, exposure to the drama had no effects, judging from the multivariate assessments of listeners and nonlisteners.

6.1.4. Behaviors. Table 2 also shows two indicators of behavior change among the sample. The first relates to "are you currently doing something or using any method of FP to delay or avoid getting pregnant?" and the other to "in the last 3 months have you discussed the practice of family planning with your family, friends, or neighbors?" Results from the multivariate estimations indicate positive drama effects, with the odds of listeners stating they currently use some form of FP (2.5 times) and that they had discussed FP with others (2.0 times) significantly higher than those of nonlisteners.

6.2. Gender Outcomes. The lower half of Table 2 reports the results of the analysis of the effect of the Ruwan Dare radio drama on the study's gender outcomes. Beginning with the outcomes pertaining to norms and gender equality, 
TABLE 1: Summary statistics on study independent, dependent, and control variables evaluation of Ruwan Dare in northern Nigeria (Kaduna, Kano, Katsina, and Sokoto), 2009.

\begin{tabular}{|c|c|c|}
\hline Key variables & $N$ & Percentage \\
\hline \multicolumn{3}{|l|}{ Independent variable } \\
\hline \multicolumn{3}{|c|}{ Listened to Ruwan Dare (exposure). } \\
\hline Nonlisteners & 193.00 & 24.30 \\
\hline Regular listeners & 456.00 & 57.50 \\
\hline \multicolumn{3}{|c|}{ Family planning (FP) and reproductive health $(\mathrm{RH})$ outcomes } \\
\hline \multicolumn{3}{|c|}{ Do you know a place where you can obtain a method of family planning (FP)? } \\
\hline No (ref.) & 222.00 & 28.00 \\
\hline Yes & 459.00 & 57.90 \\
\hline \multicolumn{3}{|c|}{ Can people reduce their chances of getting the AIDS virus by using a condom every time they have sex? } \\
\hline No, DK (ref.) & 179.00 & 22.60 \\
\hline Yes & 476.00 & 60.00 \\
\hline \multicolumn{3}{|c|}{ Is using contraception against the will of Allah/God? } \\
\hline Yes, DK (ref.) & 223.00 & 28.10 \\
\hline No & 335.00 & 42.20 \\
\hline \multicolumn{3}{|c|}{ Couples should space their children at least 2.5 to 3 years apart. } \\
\hline Disagree (ref.) & 160.00 & 20.10 \\
\hline Agree & 496.00 & 62.50 \\
\hline \multicolumn{3}{|c|}{ Can becoming pregnant every year put the mother at risk? } \\
\hline No, DK (ref.) & 239.00 & 30.10 \\
\hline Yes & 458.00 & 57.80 \\
\hline \multicolumn{3}{|c|}{ People should plan how many children they will have. } \\
\hline Disagree, DK (ref.) & 187.00 & 23.60 \\
\hline Agree & 447.00 & 56.40 \\
\hline \multicolumn{3}{|c|}{$\begin{array}{l}\text { Would you say that you approve or disapprove of couples using a family planning method to avoid getting } \\
\text { pregnant? }\end{array}$} \\
\hline Disapprove, DK (ref.) & 286.00 & 36.10 \\
\hline Approve & 411.00 & 51.80 \\
\hline \multicolumn{3}{|c|}{ What age do you think is the most appropriate for a female to start bearing children? } \\
\hline $10-19$ years (ref.) & 238.00 & 30.00 \\
\hline 20 years+ & 380.00 & 47.90 \\
\hline \multicolumn{3}{|c|}{ Would access to contraceptives encourage infidelity? } \\
\hline Yes, DK (ref.) & 369.00 & 46.50 \\
\hline No & 324.00 & 40.90 \\
\hline \multicolumn{3}{|c|}{ Do you think you will use a contraceptive method to delay or avoid pregnancy at any time in the future? } \\
\hline No (ref.) & 243.00 & 30.60 \\
\hline Yes & 70.00 & 8.80 \\
\hline \multicolumn{3}{|c|}{ Would you like to have no more children? } \\
\hline No (ref.) & 344.00 & 43.40 \\
\hline Yes & 96.00 & 12.10 \\
\hline \multicolumn{3}{|c|}{$\begin{array}{l}\text { Are you currently doing something or using any method of family planning to delay or avoid getting } \\
\text { pregnant? }\end{array}$} \\
\hline No (ref.) & 249.00 & 31.40 \\
\hline Yes & 259.00 & 32.70 \\
\hline \multicolumn{3}{|c|}{$\begin{array}{l}\text { In the last } 3 \text { months have you discussed the practice of family planning with your family, friends, or } \\
\text { neighbors? }\end{array}$} \\
\hline No (ref.) & 367.00 & 46.30 \\
\hline Yes & 329.00 & 41.50 \\
\hline
\end{tabular}


TABLe 1: Continued.

\begin{tabular}{|c|c|c|}
\hline Key variables & $N$ & Percentage \\
\hline \multicolumn{3}{|l|}{ Gender outcomes } \\
\hline \multicolumn{3}{|l|}{ Attitudes related to normative beliefs } \\
\hline \multicolumn{3}{|c|}{ Did you discuss FP with spouse in the last 3 months? } \\
\hline No (ref.) & 520.00 & 65.60 \\
\hline Yes & 273.00 & 34.40 \\
\hline \multicolumn{3}{|c|}{ Couples should share responsibility for making decisions about family size. } \\
\hline Disagree, DK (ref.) & 130.00 & 16.40 \\
\hline Agree & 538.00 & 67.80 \\
\hline \multicolumn{3}{|c|}{ What do you consider to be the ideal marriage age for a female? } \\
\hline 18 years and below (ref.) & 221.00 & 27.90 \\
\hline 19 years + & 462.00 & 58.50 \\
\hline \multicolumn{3}{|c|}{ A woman's value is judged by marriage before her first menses and by the number of children she has. } \\
\hline Agree, DK (ref.) & 473.00 & 59.60 \\
\hline Disagree & 237.00 & 29.90 \\
\hline \multicolumn{3}{|l|}{ A man is never sterile but a woman can be. } \\
\hline Agree, DK (ref.) & 465.00 & 58.60 \\
\hline Disagree & 242.00 & 30.50 \\
\hline \multicolumn{3}{|c|}{ Girls should be encouraged to continue their education to higher levels. } \\
\hline Disagree, DK (ref.) & 147.00 & 18.50 \\
\hline Agree & 565.00 & 71.20 \\
\hline \multicolumn{3}{|c|}{$\begin{array}{l}\text { Do you think that your husband/partner approves or disapproves of couples using a contraceptive method } \\
\text { to avoid pregnancy? }\end{array}$} \\
\hline Disapprove, DK (ref.) & 132.00 & 16.60 \\
\hline Approve & 246.00 & 31.00 \\
\hline \multicolumn{3}{|c|}{$\begin{array}{l}\text { Who had the final say in the decision that you would get married to or live with your (first) } \\
\text { husband/partner? }\end{array}$} \\
\hline Spouse, parents/-in law, others (ref.) & 470.00 & 59.30 \\
\hline Jointly with spouse & 135.00 & 17.00 \\
\hline \multicolumn{3}{|c|}{ Women should not be allowed to express their opinion about important family matters. } \\
\hline Agree, DK (ref.) & 266.00 & 33.50 \\
\hline Disagree & 446.00 & 56.20 \\
\hline \multicolumn{3}{|c|}{ A woman should be free to ask her husband to use a condom. } \\
\hline Disagree, DK (ref.) & 274.00 & 34.60 \\
\hline Agree & 437.00 & 55.10 \\
\hline \multicolumn{3}{|l|}{ Attitudes related to economic empowerment } \\
\hline \multicolumn{3}{|c|}{ Who in your family usually has the final say on making large household purchases? } \\
\hline Spouse, respondent, others (ref.) & 589.00 & 74.30 \\
\hline Jointly with spouse & 83.00 & 10.50 \\
\hline \multicolumn{3}{|c|}{ Who mainly decides how the money you earn will be used? } \\
\hline Spouse, respondent, others (ref.) & 184.00 & 23.20 \\
\hline Jointly with spouse & 78.00 & 9.80 \\
\hline \multicolumn{3}{|l|}{ Attitudes related to domestic violence } \\
\hline \multicolumn{3}{|c|}{$\begin{array}{l}\text { Do you think a wife is justified in refusing to have sex with her husband if she knows he has a sexually } \\
\text { transmitted infection? }\end{array}$} \\
\hline No (ref.) & 69.00 & 8.70 \\
\hline Yes & 531.00 & 67.00 \\
\hline
\end{tabular}


TABle 1: Continued.

\begin{tabular}{|c|c|c|}
\hline Key variables & $N$ & Percentage \\
\hline \multicolumn{3}{|c|}{$\begin{array}{l}\text { Do you think a wife is justified in refusing to have sex with her husband if she knows he has sex with } \\
\text { women other than his wives? }\end{array}$} \\
\hline No (ref.) & 86.00 & 10.80 \\
\hline Yes & 512.00 & 64.60 \\
\hline \multicolumn{3}{|c|}{ Do you think a wife is justified in refusing to have sex with her husband if she is tired or not in the mood? } \\
\hline No (ref.) & 220.00 & 27.70 \\
\hline Yes & 373.00 & 47.00 \\
\hline \multicolumn{3}{|c|}{ Is a husband justified in hitting or beating his wife if she goes out without telling him? } \\
\hline Yes (ref.) & 79.00 & 10.00 \\
\hline No & 619.00 & 78.10 \\
\hline \multicolumn{3}{|c|}{ Is a husband justified in hitting wife if she burns the food? } \\
\hline Yes (ref.) & 45.00 & 5.70 \\
\hline No & 654.00 & 82.50 \\
\hline \multicolumn{3}{|c|}{ Is a husband justified in hitting wife if food is not cooked on time? } \\
\hline Yes (ref.) & 54.00 & 6.80 \\
\hline No & 646.00 & 81.50 \\
\hline \multicolumn{3}{|l|}{ Control variables } \\
\hline \multicolumn{3}{|l|}{ Age } \\
\hline 40 through 59 (ref.) & 198.00 & 10.70 \\
\hline 15 through 24 & 85.00 & 42.90 \\
\hline 25 through 39 & 340.00 & 25.00 \\
\hline \multicolumn{3}{|l|}{ Sex } \\
\hline Female (ref.) & 477.00 & 60.20 \\
\hline Male & 316.00 & 39.80 \\
\hline \multicolumn{3}{|l|}{ Marital status } \\
\hline Not married (ref.) & 112.00 & 14.10 \\
\hline Currently married & 595.00 & 75.00 \\
\hline \multicolumn{3}{|l|}{ Urban/rural } \\
\hline Rural (ref.) & 420.00 & 53.00 \\
\hline Urban & 373.00 & 47.00 \\
\hline \multicolumn{3}{|l|}{ Education } \\
\hline Primary (ref.) & 139.00 & 17.50 \\
\hline Secondary & 197.00 & 24.80 \\
\hline Higher & 205.00 & 25.90 \\
\hline \multicolumn{3}{|l|}{ Ethnicity } \\
\hline Other (ref.) & 129.00 & 16.30 \\
\hline Hausa & 591.00 & 74.50 \\
\hline \multicolumn{3}{|l|}{ Sate of residence } \\
\hline Sokoto (ref.) & 199.00 & 25.10 \\
\hline Kaduna & 195.00 & 24.60 \\
\hline Kano & 199.00 & 25.10 \\
\hline Katsina & 200.00 & 25.20 \\
\hline
\end{tabular}

exposure to the drama led to a significant positive change in spousal communication about FP; listeners showed greater odds (1.9 times) than nonlisteners of holding discussions about FP issues with their spouses/partners. Likewise, on the outcome regarding shared responsibility between couples for making family size decisions, the multivariate results reveal higher odds for listeners relative to nonlisteners, implying a significant drama effect. With respect to the outcome "what do you consider to be the ideal marriage age for a female?" the effect of exposure to the drama was also positive. The odds 
TABLE 2: Estimates of the effect of a serial radio drama Ruwan Dare on family planning/reproductive health and gender outcomes in four states in northern Nigeria (Kaduna, Kano, Katsina, and Sokoto), 2009.

\begin{tabular}{|c|c|c|c|c|}
\hline & \multicolumn{2}{|c|}{ Bivariate analysis } & \multicolumn{2}{|c|}{ Multivariate analysis } \\
\hline & Odds ratio & $95 \%$ CI & Adjusted odds ratio & $95 \% \mathrm{CI}$ \\
\hline \multicolumn{5}{|l|}{ RH outcomes } \\
\hline \multicolumn{5}{|l|}{ Knowledge } \\
\hline \multicolumn{5}{|c|}{ Do you know a place where you can obtain a method of family planning $(\mathrm{FP})$ ? } \\
\hline $1=$ yes, $0=$ no, DK (ref.) & 1.39 & $0.96-2.00$ & $1.93^{* * a}$ & $1.17-3.21$ \\
\hline \multicolumn{5}{|c|}{$\begin{array}{l}\text { Can people reduce their chances of getting the AIDS virus by using a condom every } \\
\text { time they have sex? }\end{array}$} \\
\hline $1=$ yes, $0=$ no, DK (ref.) & 1.26 & $0.85-1.85$ & $1.84^{* \mathrm{~b}}$ & $1.05-3.24$ \\
\hline \multicolumn{5}{|l|}{ Attitude } \\
\hline \multicolumn{5}{|c|}{ Is using contraception against the will of Allah/God? } \\
\hline $1=$ yes, $0=$ no, DK (ref.) & 1.25 & $0.85-1.84$ & $1.92^{* \mathrm{c}}$ & $1.10-3.36$ \\
\hline \multicolumn{5}{|c|}{ Couples should space their children at least 2.5 to 3 years apart. } \\
\hline $1=$ agree, $0=$ disagree (ref.) & $2.03^{* * *}$ & $1.37-3.00$ & $2.91^{* * *}$ & $1.63-5.19$ \\
\hline \multicolumn{5}{|c|}{ Can becoming pregnant every year put the mother at risk? } \\
\hline $1=$ yes, $0=$ no, DK (ref.) & 1.27 & $0.89-1.83$ & $1.87^{* \mathrm{c}}$ & $1.08-3.24$ \\
\hline \multicolumn{5}{|c|}{ People should plan how many children they will have. } \\
\hline $1=$ agree, $0=$ disagree $($ ref.) & $1.68^{* *}$ & $1.15-2.46$ & $2.63^{* * *}$ & $1.47-4.68$ \\
\hline \multicolumn{5}{|c|}{$\begin{array}{l}\text { Would you say that you approve or disapprove of couples using a family planning } \\
\text { method to avoid getting pregnant? }\end{array}$} \\
\hline $1=$ approve, $0=$ disapprove, $\mathrm{DK}$ (ref.) & $1.60^{* *}$ & $1.13-2.28$ & $1.81^{*}$ & $1.12-2.93$ \\
\hline \multicolumn{5}{|c|}{ What age do you think is the most appropriate for a female to start bearing children? } \\
\hline $1=20$ years,$+ 0=10-19$ years $($ ref.) & 0.83 & $0.57-1.22$ & 0.78 & $0.44-1.37$ \\
\hline \multicolumn{5}{|c|}{ Would access to contraceptives encourage infidelity? } \\
\hline $1=$ no, $0=$ yes, $\mathrm{DK}=0$ (ref.) & 1.12 & $0.79-1.58$ & 1.24 & $0.80-1.92$ \\
\hline \multicolumn{5}{|l|}{ Intentions } \\
\hline \multicolumn{5}{|l|}{ Would you like to have no more children? } \\
\hline $1=$ yes, $0=$ no, DK (ref.) & 1.51 & $0.86-2.64$ & 1.20 & $0.56-2.57$ \\
\hline \multicolumn{5}{|c|}{$\begin{array}{l}\text { Do you think you will use a contraceptive method to delay or avoid pregnancy at } \\
\text { any time in the future? }\end{array}$} \\
\hline $1=$ yes, $0=$ no, DK (ref.) & 1.15 & $0.61-2.17$ & 1.97 & $0.75-5.19$ \\
\hline \multicolumn{5}{|l|}{ Behavior } \\
\hline \multicolumn{5}{|c|}{$\begin{array}{l}\text { Are you currently doing something or using any method of family planning to delay } \\
\text { or avoid getting pregnant? }\end{array}$} \\
\hline $1=$ yes, $0=$ no, $\mathrm{DK}($ ref.) & $2.37^{* * *}$ & $1.56-3.60$ & $2.45^{* *}$ & $1.336-4.41$ \\
\hline \multicolumn{5}{|c|}{$\begin{array}{l}\text { In the last } 3 \text { months have you discussed the practice of family planning with your } \\
\text { family, friends, or neighbors? }\end{array}$} \\
\hline $1=$ yes, $0=$ no, DK (ref.) & $2.07^{* * *}$ & $1.45-2.95$ & $2.00^{* * *}$ & $1.23-3.26$ \\
\hline \multicolumn{5}{|l|}{ Gender outcomes } \\
\hline \multicolumn{5}{|c|}{ Attitudes and behaviors related to normative beliefs and gender equality } \\
\hline \multicolumn{5}{|l|}{ Discussed FP with spouse in the last 3 months. } \\
\hline $1=$ yes, $0=$ no, DK (ref.) & $1.98^{* * *}$ & $0.37-2.85$ & $1.89^{*}$ & $1.17-3.05$ \\
\hline \multicolumn{5}{|c|}{ Couples should share responsibility for making decisions about family size. } \\
\hline $1=$ yes, $0=$ no, DK (ref.) & $1.77^{* *}$ & $1.17-2.70$ & $2.06^{*}$ & $1.10-3.87$ \\
\hline \multicolumn{5}{|c|}{ What do you consider to be the ideal marriage age for a female? } \\
\hline $1=19$ years,$+ 0=18$ years and below (ref.) & 1.04 & $0.71-1.50$ & $1.73^{* \mathrm{~d}}$ & $1.02-2.93$ \\
\hline $\begin{array}{l}\text { A woman's value is judged by marriage before } \\
\text { children she has. }\end{array}$ & & & & \\
\hline $1=$ disagree, 0 = agree (ref.) & $0.67^{*}$ & $0.47-0.96$ & $0.89^{\mathrm{e}}$ & $0.56-1.42$ \\
\hline
\end{tabular}


TABLE 2: Continued.



Differences between surveys and between listeners and nonlisteners are significant at ${ }^{* * *} P<.001,{ }^{* *} P<.01,{ }^{*} P<.05$.

${ }^{a}$ means the introduction of the correlates, state, education, and ethnicity turned the effect of drama exposure significant; ${ }^{b}$ means the introduction of the correlate, education turned the effect of drama exposure significant; ${ }^{c}$ means the introduction of the correlate, state turned the effect of drama exposure significant; ${ }^{\mathrm{d}}$ means the introduction of the correlate, current marital status turned the effect of drama exposure significant; ${ }^{\mathrm{e}}$ means the introduction of the correlate, current marital status turned the effect of drama exposure nonsignificant; ${ }^{\mathrm{f}}$ means the introduction of the correlate, ethnicity turned the effect of drama exposure significant.

of listeners agreeing with the statement were almost twice greater than those of nonlisteners. It is of note to mention that the bivariate association between exposure to the drama and this latter attitudinal gender outcome was not statistically significant, but it became significant when current marital status was controlled for in the multivariate model, suggesting that the relationship is conditioned by differences in marital status. Similarly, the importance of controlling for marital status was also observed on the association between exposure to the drama and the outcome: "a woman's value is judged by marriage before her first menses and by the number of children she has." The direction of the bivariate effect was negative, but this apparent effect was due to a failure to control for marital status in the model and once this control was introduced, the relationship became statistically nonsignificant. According to the table, the remaining five attitudinal outcomes regarding girls' education, sterility, approval of FP, marriage decisions, wife's ability to ask her husband to use condoms, and the appropriateness for women to express their opinions on family matters were not affected by the drama.

In terms of the two gender outcomes associated with attitudes toward economic empowerment, the drama's impact 


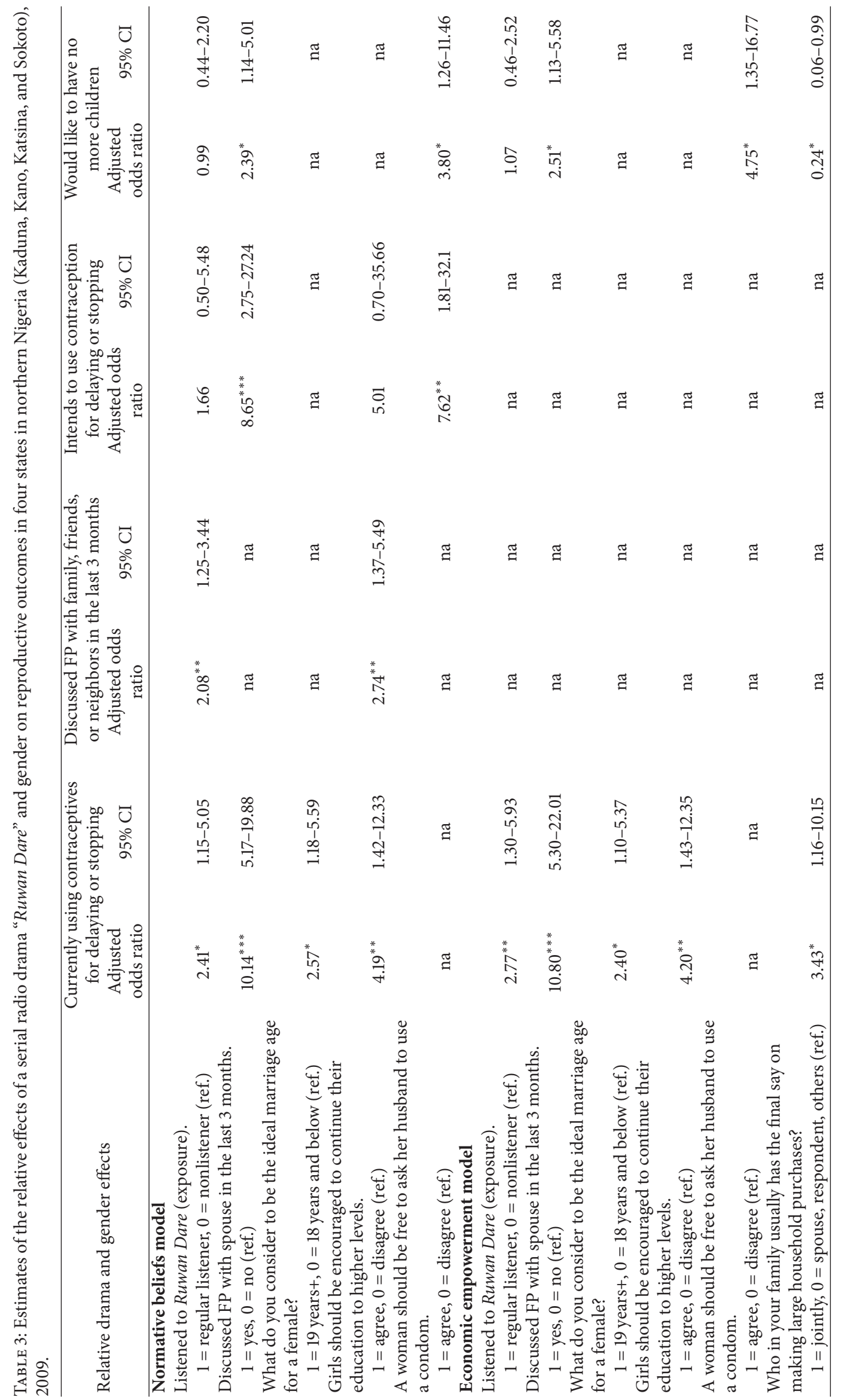




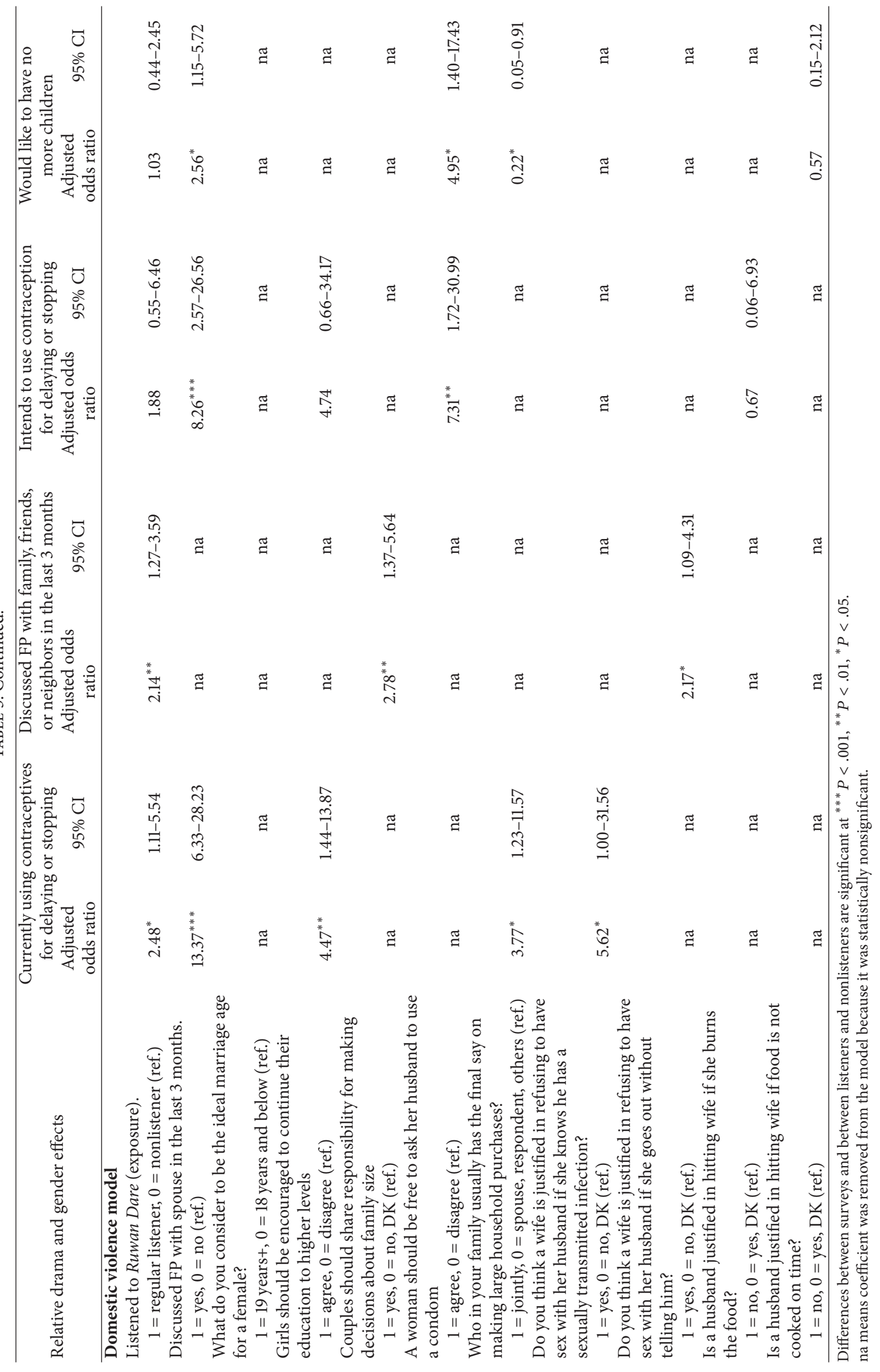


was null. On the other hand, significant drama effects on the outcomes reflecting domestic violence were generally observed. Based on the multivariate estimates, the odds of listeners agreeing with the statement "do you think a wife is justified in refusing to have sex with her husband if she knows he has a sexually transmitted infection?" were 3.1 times greater than those of nonlisteners. On the following outcomes: "do you think a wife is justified in refusing to have sex with her husband if she knows he had sex with women other than his wives?" and "do you think a wife is justified in refusing to have sex with her husband if she is tired or not in the mood?" the respective odds for listeners relative to nonlisteners agreeing with the statements were 2.9 and 1.8. Furthermore, results show that the latter outcome was mediated through ethnicity because the association turned significant only after the introduction of the ethnicity variable in the estimation model, even as the effect of this correlate was nonsignificant. Conversely, no significant differences between listeners and nonlisteners were found regarding disagreement with the statement "is a husband justified in hitting or beating his wife if she goes out without telling him?"

6.3. Relative Effect of Gender on Reproductive Outcomes. To investigate the relative effect of gender on the reproductive outcomes, the measures for each of the three different dimensions of gender (normative beliefs, attitudes toward economic empowerment, and domestic violence) were added to the various models estimating the net effect of the drama (i.e., controlling for all the study correlates) on the reproductive outcomes. For each reproductive outcome, the gender measures were sequentially incorporated in three models. In the first model, all the gender variables reflecting normative beliefs surrounding gender equality were introduced. The second model added the gender measures denoting economic empowerment, and the third model further added the domestic violence measures. For parsimony, only the gender measures that turned out to be significant in at least one of the three models were generally retained. In instances where none of the respective gender predictors being considered under a particular model were statistically significant, at least one measure was retained to keep the model. For comparison, the relative effects of the drama estimated in the three models are also presented, whether significant or not. The results are shown in Tables 3 through 5 for twelve RH outcomes.

Table 3 shows the relative effect of the three dimensions of the gender predictors on the two behavioral and the two intentional RH outcomes, namely, "are you currently doing something or using any method of FP to delay or avoid getting pregnant?"; "in the last 3 months have you discussed the practice of FP with your family, friends, or neighbors?"; "do you think you will use a contraceptive method to delay or avoid pregnancy at any time in the future?"; and "would like to have no more children." Results indicate positive effects for several of the gender predictors in each of the three models on current FP use. In model 1 (norms regarding gender equality), discussion of FP with spouse and attitudes toward ideal age at marriage for women and encouraging girls' continued schooling had a positive impact on current use of contraceptives. In the second economic empowerment model, in addition to the gender effects observed to be significant in the first model, spouses' joint decision on large household purchases was also positively associated with the $\mathrm{RH}$ outcome. In the third model (domestic violence), agreement with wife's justification in denying her husband sex if he has a sexually transmitted infection, in addition to the significant gender effects in the two models above, had a significant effect on current use. Exposure to the drama continued to significantly impact current use of FP, with the presence of the gender predictors as well as the correlates in the model.

Unlike current use of FP, the effects of the gender predictors on discussion of FP with family, friends, and neighbors were quite modest. In the first gender model, only encouraging girls' continued schooling positively predicted this RH outcome. In the third model, respondents' agreement with "couples should share responsibility for making decisions about family size" and disagreement with "is a husband justified in hitting or beating his wife if she goes out without telling him?" positively impacted discussion of FP with family, friends, and neighbors among respondents while none of the gender predictors considered in the second economic empowerment model had an impact on the outcome. As with current FP use, the relative effect of the drama on the outcome remained positive and significant.

In contrast, the lack of association between exposure to the drama and the two intentional RH outcomes investigated (observed in Table 2) persisted after the three sets of gender predictors were incorporated in the respective models. Yet, two gender predictors in the normative beliefs model, spousal discussion of FP in the last three months and agreement among respondents with the statement "a woman should be free to ask her husband to use a condom," were positively associated with intention to use FP in the future. The same two gender predictors continued to positively impact the two intentional outcomes in the final domestic violence model while none of the domestic violence predictors were influential. However, in the case of the latter outcome "would like to have no more children," the gender predictor concerning joint decision between spouses on large household purchases also had a negative effect.

In Table 4, we show four of the seven $\mathrm{RH}$ outcomes reflecting attitudinal changes, specifically, "is using contraception against the will of Allah/God?"; "can becoming pregnant every year put the mother at risk?"; "couples should space their children at least 2.5 to 3 years apart"; and "people should plan how many children they will have." Surprisingly, the effects of the drama relative to the gender predictors on the first two attitudinal outcomes were nonsignificant, surprisingly, because the drama effect was significantly positive in the presence of controls only, as Table 2 shows. This means that for these two outcomes the gender mediators are more important than exposure to the drama. On the other hand, various gender predictors (discussion of FP with spouse in the last three months, agreement with "what do you consider to be the ideal marriage age for a female?", and disagreement with "women should not be allowed to express their opinion about important family matters") had a positive effect on 


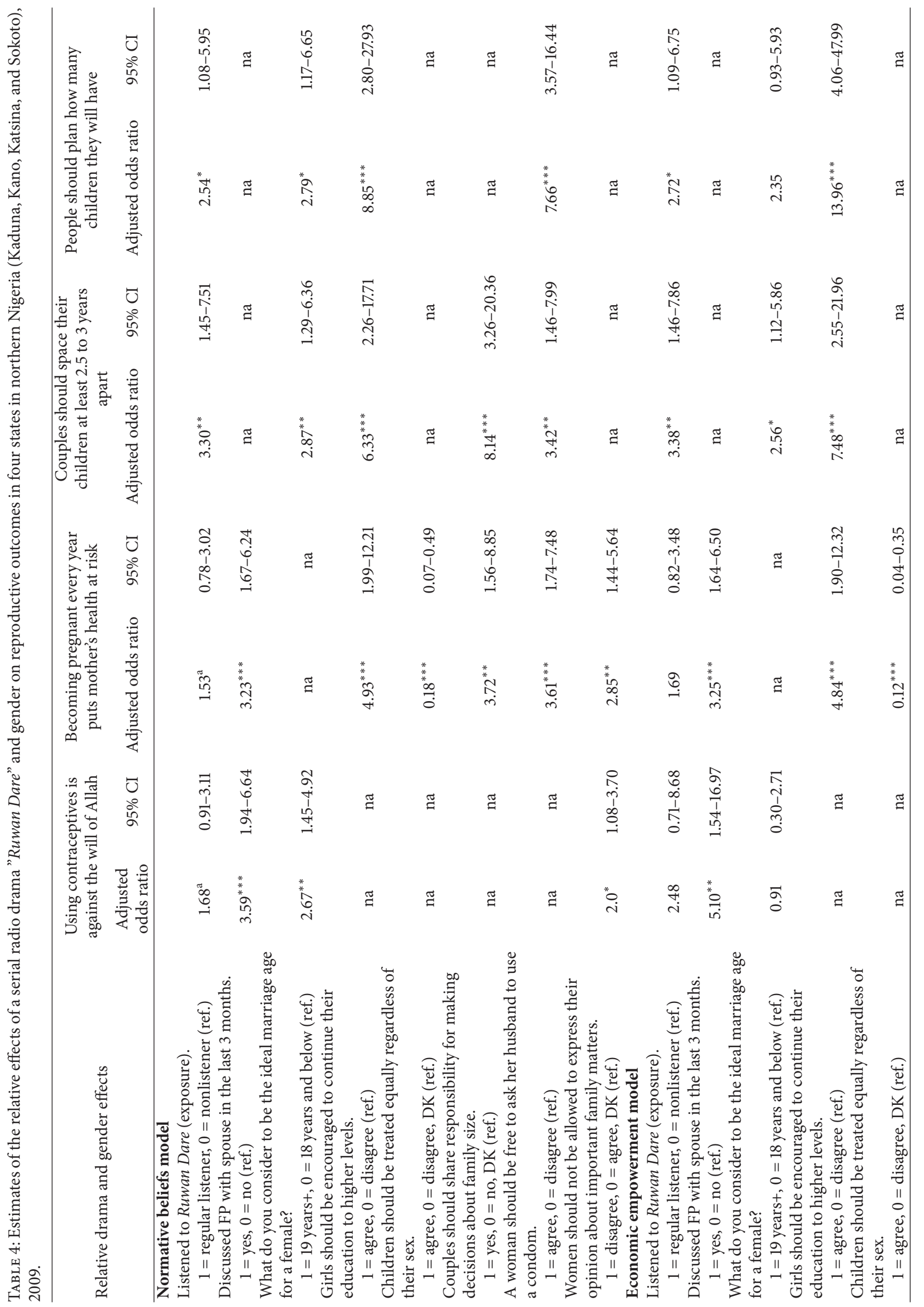




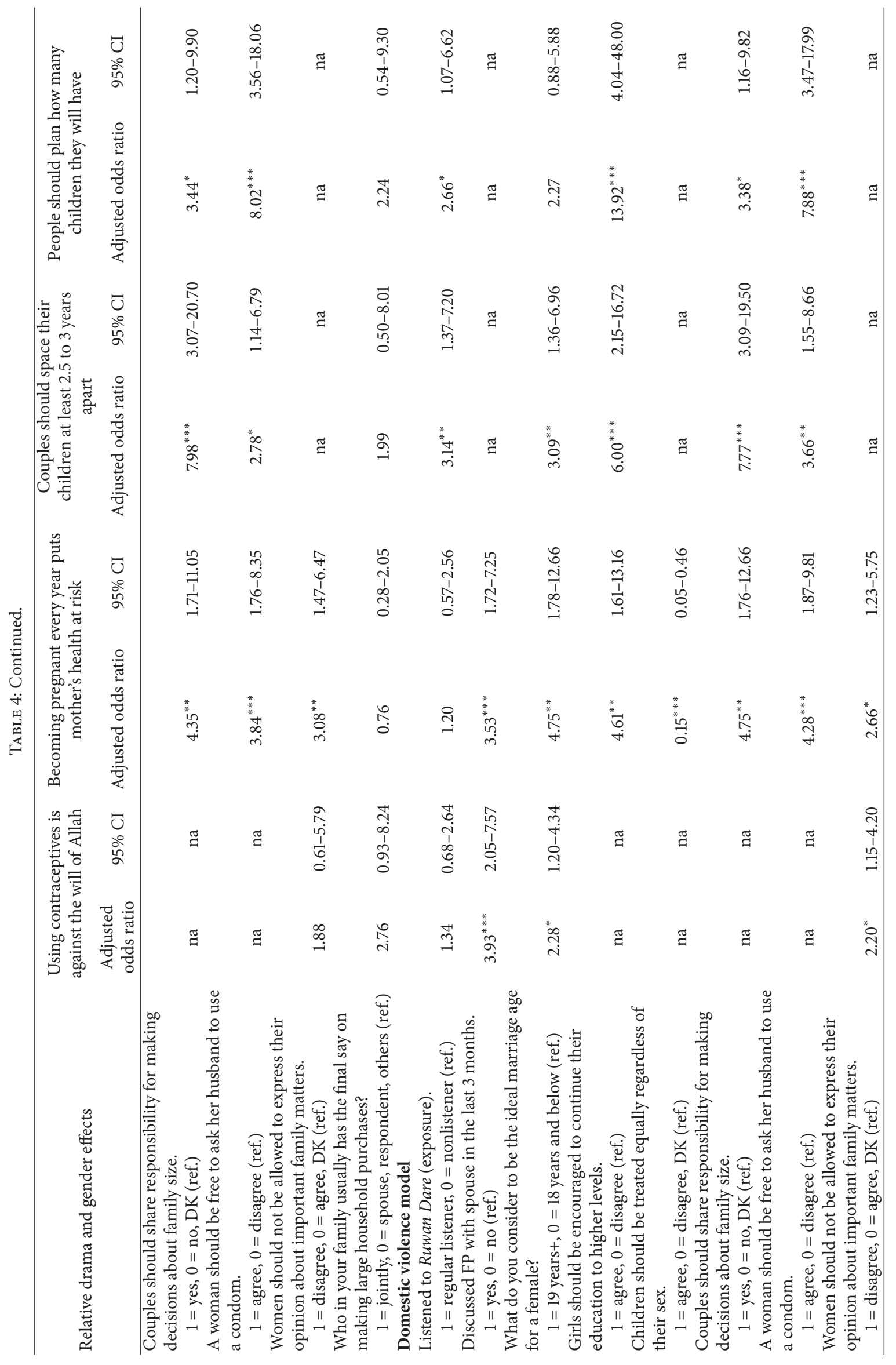




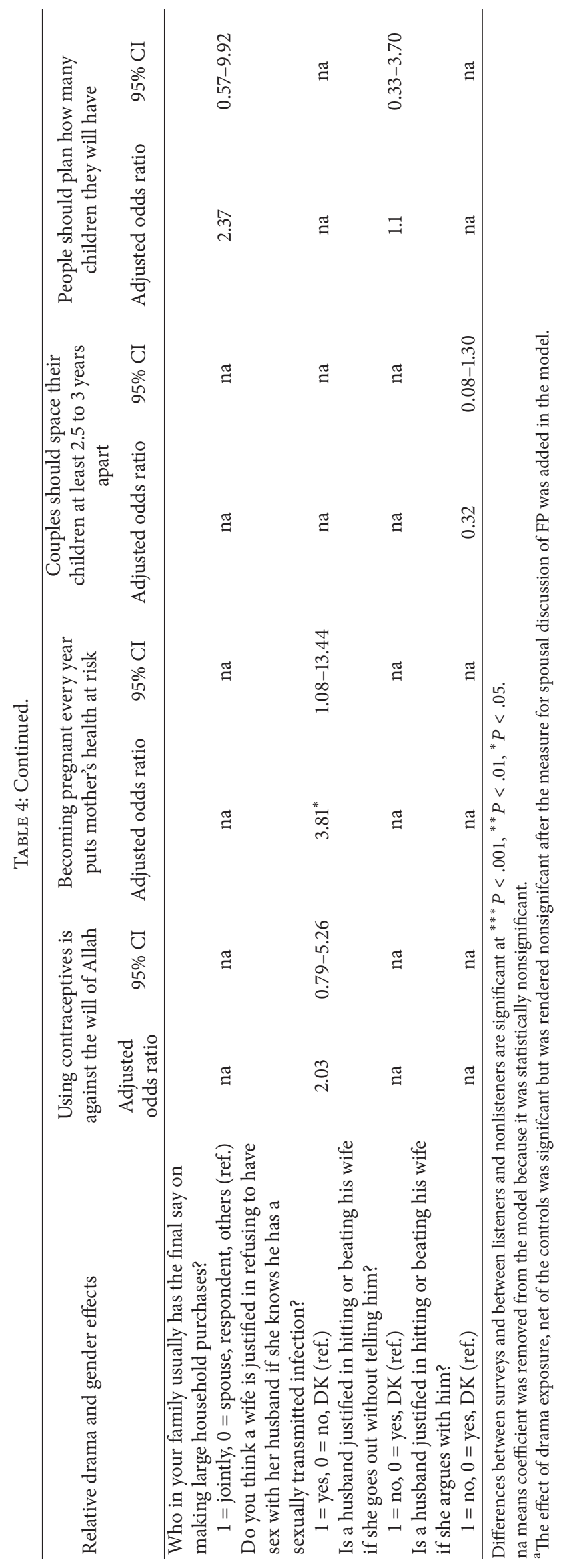




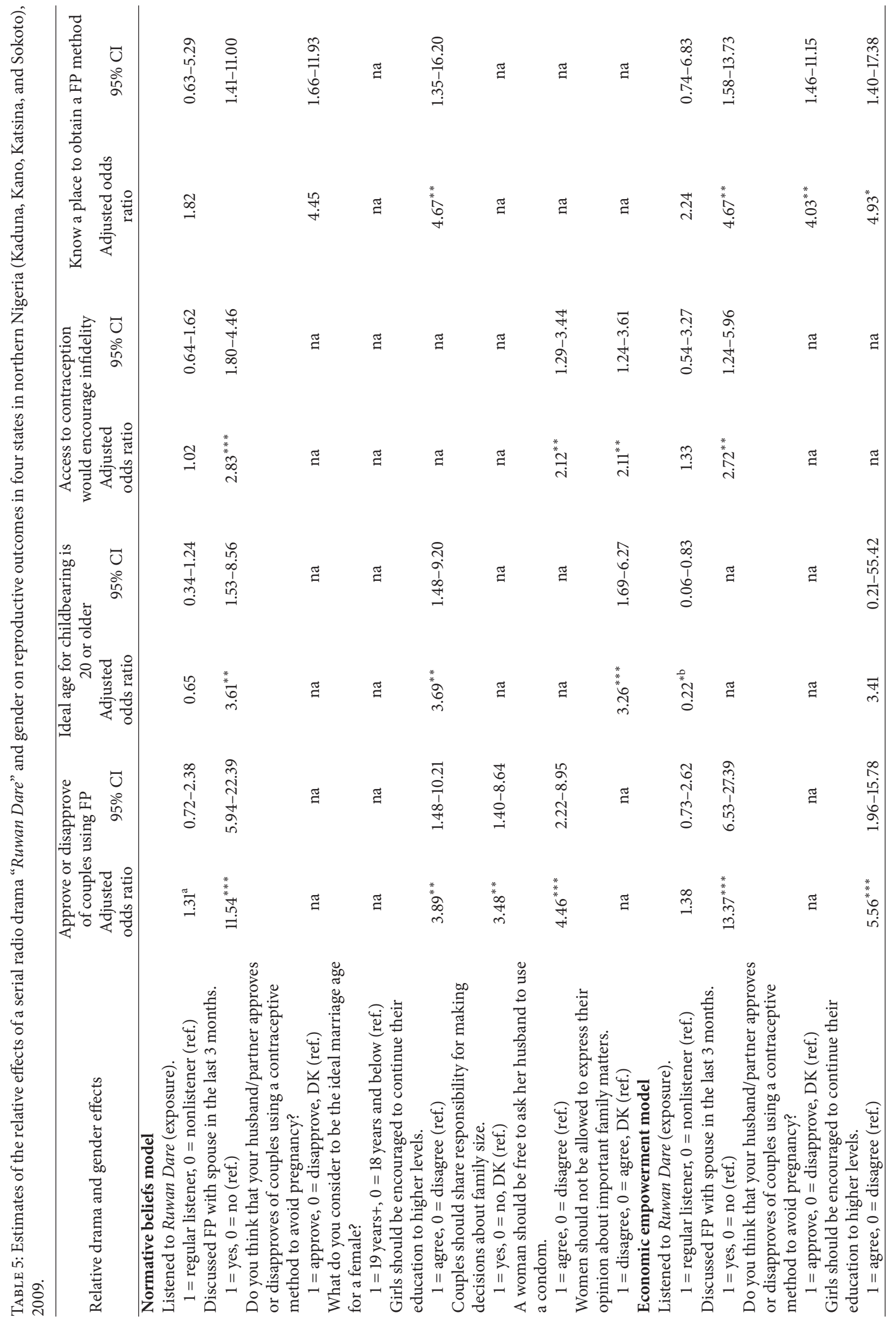









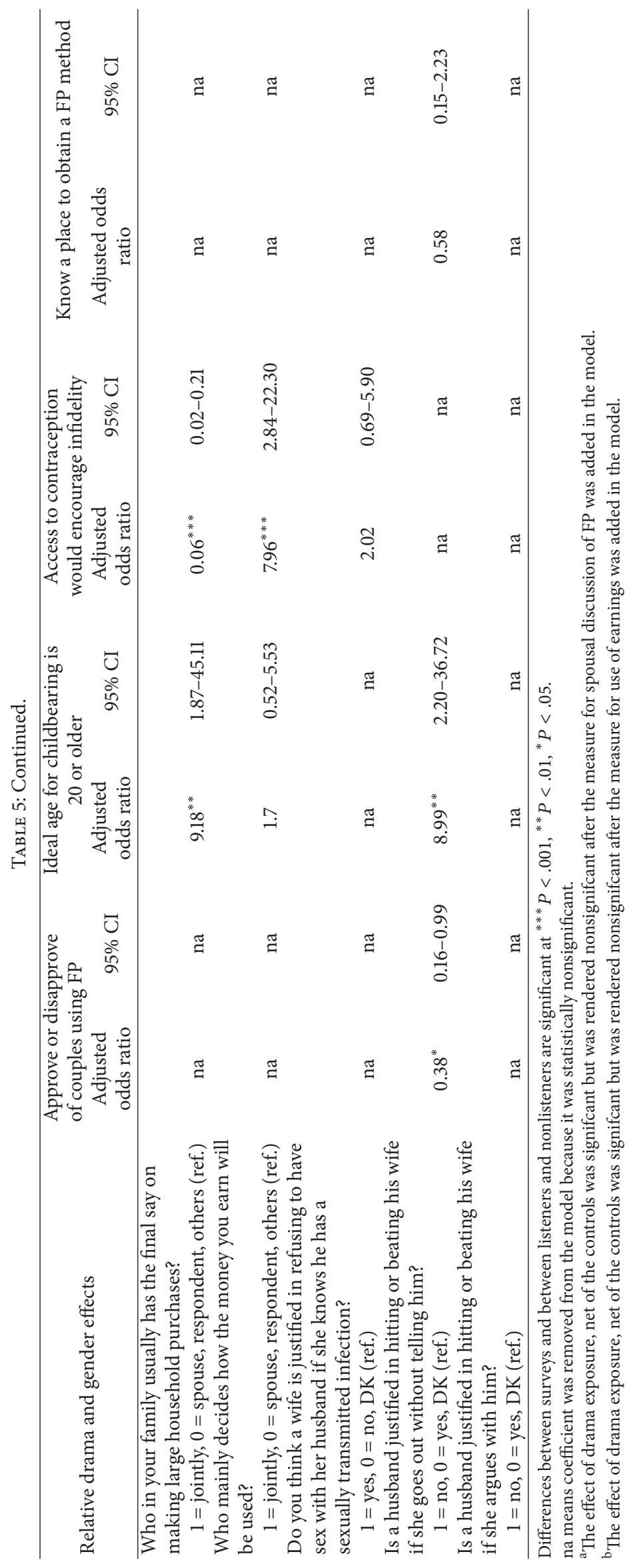


the first outcome, "is using contraceptives against the will of Allah/God?" Similarly, with respect to the outcome "can becoming pregnant every year put the mother at risk?" a host of gender predictors, particularly those considered under the normative beliefs model, had positive effects. An exception to this general observation is the effect of the predictor "children should be treated equally regardless of their sex" on the outcome, which turned out to be negative.

In terms of the other two outcomes, "couples should space their children at least 2.5 to 3 years apart" and "people should plan how many children they will have," the relative effect of the drama, like in the models in Table 2 that adjusted for the correlates only, remained positive and strong throughout the three gender predictor models. A set of gender predictors but generally different than those discussed above were positively associated with the outcomes. These include respondents' agreement with "girls should be encouraged to continue their education to higher levels"; "couples should share responsibility for making family size decisions"; "a woman should be free to ask her husband to use a condom"; and "what do you consider to be the ideal marriage age for a female?" (only in the case of "couples should space their children at least 2.5 to 3 years apart").

Table 5 presents the final set of RH outcomes examined in the study: three pertaining to changes in attitudes (1) "would you say that you approve or disapprove of couples using a FP method to avoid getting pregnant?"; (2) "what age do you think is most appropriate for a female to start bearing children?"; and (3) "access to contraception would encourage infidelity" and one relating to knowledge "do you know a place where you can obtain a method of FP?" about $\mathrm{RH}$ issues. Based on the table, the drama had no impact on all the outcomes, with the gender predictors in the models even though the drama had a positive effect on the latter two outcomes with just the correlates in the models. On the other hand, some of the gender predictors showed positive associations with the four outcomes. For instance, in the final model, the predictor "discussed FP with spouse in the last three months" had positive effects on the first, third, and fourth RH outcomes; respondents' agreement with the predictor "girls should be encouraged to continue their education to higher levels" positively impacted the first and the fourth outcomes; and "who mainly decides how the money you earn will be used?" was positively associated with the second and third outcomes.

A spouse's approval of FP had a positive effect on the fourth outcome among respondents. Agreement with "couples should share responsibility for making family size decisions" and "a woman should be free to ask her husband to use a condom" both had a positive effect on the first outcome and "who mainly decides how the money you earn will be used?" positively predicted the third outcome. Joint spousal decisions on the purchase of large household items showed a positive impact on the second outcome and a negative impact on third outcome while disagreement among respondents with "is a husband justified in hitting or beating his wife if she goes out without telling him" had a positive effect on the second outcome but negatively impacted the first outcome.

\section{Discussion and Conclusion}

Sociocultural factors, including inegalitarian gender relations, have limited the success of RH behavior change communication programs in northern Nigeria. Population Media Center developed and aired Ruwan Dare, a Sabido-style radio drama in four states in the region, Kaduna, Kano, Katsina, and Sokoto, to mitigate these sociocultural and gender challenges that tend to hinder the adoption of positive reproductive health attitudes and behaviors. The study sets out to evaluate the impact of Ruwan Dare on two sets of outcomes, RH and gender issues pertaining to $\mathrm{RH}$, by comparing listeners and nonlisteners on changes in knowledge, attitudes, intentions, and behaviors surrounding the two groups of outcomes.

With respect to the study's second research question and in concert with past studies conducted in Africa [2-6, 10, 13, $16,18]$ and elsewhere $[7,8,11,12,14,15,17]$ the results suggest that the radio drama succeeded in modifying attitudes toward FP/RH. Several reproductive outcomes are in the anticipated direction in terms of exposure to the drama, most notably the behavioral, knowledge, and most of the attitudinal outcomes investigated. The success of the drama can be attributed to the Sabido methodology, a unique and transformative approach that utilizes audience research and long-running serial dramas to allow bonding between audience and the characters, and a whole society approach that has the capacity to reach a wide audience $[5,53,54]$. These results, confirmed by the program's analysis of the listener diaries, highlight the strong identification of the audience with the storylines on $\mathrm{FP}$ and $\mathrm{RH}$. One striking finding from the analysis of listener diaries was the case of Maimuna, a 25-year-old mother of five who not only was an avid listener but also gradually persuaded her husband to begin listening as well. In her diary, she narrated how the drama forged a healthy discussion of the benefits of FP with her husband, which ultimately led her and her husband to seek FP services.

Similarly and in response to the study's research question on gender, Ruwan Dare impacted gender issues associated with $\mathrm{FP} / \mathrm{RH}$. However, the impact was not as widespread across the gender outcomes relative to that observed for the RH outcomes, highlighting the multilayered and complexity of the role of gender in reproductive behavior. The study therefore advocates for greater programming on gender in $\mathrm{RH}$ to both sustain gains already made and extend these gains to other reproductive health outcomes.

The study also examined the mediating effect of gender on the association between exposure to the drama and $\mathrm{RH}$ outcomes by including measures of three dimensions of gender and the drama exposure variable as predictors in the same model while controlling for the seven study correlates. In this way, the study was able to establish the relative effect of both the drama and gender on RH outcomes. The findings are very insightful. For the twelve RH outcomes evaluated, the relative effects of the drama (i.e., in the presence of the gender predictors in addition to the study correlates) were consistent with the net drama effects (i.e., in the presence of the correlates only) on eight of them. Like the net effects, the relative drama effects continued to be positive for four outcomes (current use of FP; FP discussion with family, friends, 
and neighbors; birth intervals of 2.5 to 3 years; the importance of couples planning how many children to have) and nil for another four (intention to use contraceptives; want no more children; ideal age for childbearing is 20 years or older; access to contraceptives would encourage infidelity). However, for the remaining four outcomes ("using contraceptives is against the will of Allah," "becoming pregnant every year puts the mother's health at risk," "should couples use contraceptives to avoid pregnancy," and "knowledge of a place to obtain a FP method"), the drama effect lost its initial positive significance to the gender predictors (see Tables 2-5).

As indicated by Tables $3-5$, the most illuminating finding is that all twelve $\mathrm{RH}$ outcomes were positively impacted by many of the gender predictors. These findings on the significance of gender in $\mathrm{RH}$ are consistent with the general interpretation from earlier studies conducted in Nigeria [20, $46,51]$. The findings also confirm claims in the broader demographic literature $[21,28,39]$ and by the international development community [19] regarding the critical role of gender in RH outcomes. Similarly, the strong positive effect of FP communication between spouses and to a lesser extent those of joint decision of spouses on $\mathrm{RH}$ decisions corroborates assertions by authors [22, 36, 37] of the importance of spousal communication and agreement on reproductive outcomes.

The divergent effects of the gender predictors on the $\mathrm{RH}$ outcomes support the study's detailed focus on a comprehensive set of predictors. Had we examined just a few predictors or had we constructed composite indices of the predictors, we would have missed much of the findings on the relative effect of gender on RH issues. Finally, the findings on the mediating effects of this large number of indicators of gender afford researchers an opportunity to better determine which group of gender measures to include in composite indices, depending on the outcomes being investigated.

\section{Limitations}

Despite the study's achievements, a number of limitations deserve comment. Randomized controlled experimental design is the gold standard for the evaluation of behavioral change programs. However, the radio drama was aired throughout the target region, thereby precluding the use of randomized controlled designs. The pretest/posttest crosssectional design adopted in the evaluation of drama tends to introduce threats of validity [55] and bias in the data, from both the self-reporting of sensitive information and selfselection of participants (e.g., respondents who habitually listen to radio health programs may also have greater tendency to listen to the drama). To ascertain if the data suffer from selfselection, we determined how listenership to general radio health programs was associated with listenership to Ruwan Dare. We found that, among regular listeners to Ruwan Dare, 36 percent also listened to general health programs on the radio compared with $34 \%$ of nonlisteners, and these differences were nonsignificant statistically, ruling out any serious bias from self-selection.

\section{Conflict of Interests}

The authors declare that there is no conflict of interests regarding the publication of this paper.

\section{Acknowledgment}

PMC would like to thank the David and Lucile Packard Foundation for funding the drama program, Ruwan Dare.

\section{References}

[1] S. Agha, "A quasi-experimental study to assess the impact of four adolescent sexual health interventions in Sub-Saharan Africa," International Family Planning Perspectives, vol. 28, no. 2, pp. 67-70+113-118, 2002.

[2] S. Agha and R. van Rossem, "Impact of mass media campaigns on intentions to use the female condom in Tanzania," International Family Planning Perspectives, vol. 28, no. 3, pp. 151-158, 2002.

[3] A. Bankole, G. Rodríguez, and C. F. Westoff, "Mass media messages and reproductive behaviour in Nigeria," Journal of Biosocial Science, vol. 28, no. 2, pp. 227-239, 1996.

[4] N. Gupta, C. Katende, and R. Bessinger, "Association of mass media exposure on family planning attitudes and practices in Uganda," Measure Evaluation Working Paper WP-0367, Carolina Population Center, University of North Carolina at Chapel Hill, Chapel Hill, NC, USA, 2003.

[5] M. N. Jato, C. Simbakalia, J. M. Tarasevich, D. N. Awasum, C. N. B. Kihinga, and E. Ngirwamungu, "The impact of multimedia family planning promotion on the contraceptive behavior of women in Tanzania," International Family Planning Perspectives, vol. 25, no. 2, pp. 60-67, 1999.

[6] T. T. Kane, M. Gueye, I. Speizer, S. Pacque-Margolis, and D. Baron, "The impact of a family planning multimedia campaign in Bamako, Mali," Studies in Family Planning, vol. 29, no. 3, pp. 309-323, 1998.

[7] D. L. Kincaid, A. P. Merritt, L. Nickerson, S. de Castro Buffington, M. P. P. de Castro, and B. M. de Castro, "Impact of a Mass Media Vasectomy Promotion Campaign in Brazil," International Family Planning Perspectives, vol. 22, no. 4, pp. 169-175, 1996.

[8] I. Olenick, "Women's exposure to mass media is linked to attitudes toward contraception in Pakistan, India and Bangladesh," International Family Planning Perspectives, vol. 26, no. 1, pp. 4850, 2000.

[9] P. Piotrow, D. Kincaid, M. Hindin et al., "Changing men's attitudes and behavior: the Zimbabwe male motivation project," Studies in Family Planning, vol. 23, no. 6, pp. 365-375, 1992.

[10] E. M. Rogers, P. W. Vaughan, R. M. A. Swalehe, N. Rao, P. Svenkerud, and S. Sood, "Effects of an entertainment-education radio soap opera on family planning behavior in Tanzania," Studies in Family Planning, vol. 30, no. 3, pp. 193-211, 1999.

[11] C. L. Shefner-Rogers and S. Sood, "Involving husbands in safe motherhood: effects of the Suami SIAGA Campaign in Indonesia," Journal of Health Communication, vol. 9, no. 3, pp. 233-258, 2004.

[12] R. A. Smith, E. Downs, and K. Witte, "Drama theory and entertainment education: exploring the effects of a radio drama on behavioral intentions to limit HIV transmission in Ethiopia," Communication Monographs, vol. 74, no. 2, pp. 133-153, 2007. 
[13] S. Sood and D. Nambiar, "Comparative cost-effectiveness of the components of a behavior change communication campaign on HIV/AIDS in North India," Journal of Health Communication, vol. 11, no. 2, pp. 143-162, 2006.

[14] D. Storey, M. Boulay, Y. Karki, K. Heckert, and D. M. Karmacharya, "Impact of the integrated radio communication project in Nepal, 1994-1997," Journal of Health Communication, vol. 4, no. 4, pp. 271-294, 1999.

[15] T. W. Valente and W. P. Saba, "Campaign exposure and interpersonal communication as factors in contraceptive use in Bolivia," Journal of Health Communication, vol. 6, no. 4, pp. 303-322, 2001.

[16] T. W. Valente, Y. M. Kim, C. Lettenmaier, W. Glass, and Y. Dibba, "Radio promotion of family planning in The Gambia," International Family Planning Perspectives, vol. 20, no. 3, pp. 96100, 1994.

[17] P. W. Vaughan, A. Regis, and E. St. Catherine, "Effects of an entertainment-education radio soap opera on family planning and HIV prevention in St. Lucia," International Family Planning Perspectives, vol. 26, no. 4, pp. 148-157, 2000.

[18] C. F. Westoff and A. Bankole, "Mass media and reproductive behavior in Africa," Demographic and Health Surveys Analytical Reports 2, Macro International Inc., Calverton, Md, USA, 1997.

[19] United Nations, "Program of action of the 1994 international conference of population and development, chapters I-VIII," Population and Development Review, vol. 21, pp. 187-213, 1995.

[20] M. M. Kritz, P. Makinwa-Adebusoye, and D. T. Gurak, "The role of gender context in shaping reproductive behavior in Nigeria," in Women's Empowerment and Demographic Processes: Moving Beyond Cairo, H. B. Presser and G. Sen, Eds., Oxford University Press, Oxford, UK, 2000.

[21] K. O. Mason and H. L. Smith, "Husbands' versus wives' fertility goals and use of contraception: the influence of gender context in five asian countries," Demography, vol. 37, no. 3, pp. 299-311, 2000.

[22] U. C. Isiugo-Abanihe, "Reproductive motivation and familysize preferences among Nigerian men," Studies in Family Planning, vol. 25, no. 3, pp. 149-161, 1994.

[23] R. van Rossem and D. Meekers, "An evaluation of the effectiveness of targeted social marketing to promote adolescent and young adult reproductive health in Cameroon," AIDS Education and Prevention, vol. 12, no. 5, pp. 383-404, 2000.

[24] United Nations, Millenium Development Goals, United Nations, New York, NY, USA, 2012.

[25] J. Bongaarts, "Fertility transitions in developing countries: progress or stagnation?" Studies in Family Planning, vol. 39, no. 2, pp. 105-110, 2008.

[26] Guttmacher, "Fertility declines have stalled in many countries in Sub-Saharan Africa," International Family Planning Perspectives, vol. 34, no. 3, 2008.

[27] D. Shapiro and T. Gebreselassi, "Fertility transition in SubSaharan Africa: evidence from the demographic and health surveys," African Population Studies, vol. 22-23, no. 1, pp. 3-23, 2008.

[28] A. M. Basu, "Why does education lead to lower fertility? A critical review of some of the possibilities," World Development, vol. 30, no. 10, pp. 1779-1790, 2002.

[29] Population Reference Bureau (PRB), 2012, http://www.prb.org/ DataFinder.
[30] NPC and ICF Macro, Nigeria Demographic and Health Survey 2008. National Population Commission (NPC) [Nigeria] and ICF Macro, National Population Commission and ICF Macro, Abuja, Nigeria, 2009.

[31] G. Sedgh, A. Bankole, B. Oye-Adeniran, I. F. Adewole, S. Singh, and R. Hussain, "Unwanted pregnancy and associated factors among Nigerian women.", International family planning perspectives, vol. 32, no. 4, pp. 175-184, 2006.

[32] John Hopskins University, "Kano Advocacy Booklet," in The European Journal of Contraception and Reproductive Health Care, Johns Hopkins University, Ed., Johns Hopkins University, Kano, Nigeria, 2012.

[33] M. A. Ijaiya, A. G. Rahman, A. P. Aboyeji et al., "Vesicovaginal fistula: a review of nigerian experience," West African Journal of Medicine, vol. 29, no. 5, pp. 293-298, 2010.

[34] C. Chukuezi, "Sociocultural factors associated with maternal mortality in Nigeria," Research Journal of Social Sciences, vol. 1, no. 5, pp. 22-26, 2010.

[35] Demographic and Health Surveys, StatsCompiler, 2012, http://www.measuredhs.com/Data/.

[36] A. C. Ezeh, "The influence of spouses over each other's contraceptive attitudes in Ghana," Studies in Family Planning, vol. 24, pp. 355-368, 1997.

[37] C. Flink, "Spousal communication and contraceptive use in rural Nepal: an event history analysis," Studies in Family Planning, vol. 42, no. 2, pp. 83-92, 2011.

[38] S. J. Jejeebhoy, Women's Education, Autonomy, and Reproductive Behavior: Experience from Developing Countries, Clarendon Press, Oxford, UK, 1995.

[39] K. O. Mason, "The impact of womens position on demographic change during the course of development," in Women's Position and Demographic Change, N. Federici, K. O. Mason, and S. Sogner, Eds., Clarendon Press, Oxford, UK, 1993.

[40] N. E. Riley, "Gender, power, and population change," Population Bulletin, vol. 52, no. 1, pp. 2-46, 1997.

[41] T. Castro-Martin and F. Juarez, "The influence of women's education on fertility in Latin America: in search of explanations," International Family Planning Perspectives, vol. 21, no. 2, pp. $52-$ 57, 1995.

[42] J. C. Caldwell, "Mass education as a determinant of the timing of fertility decline," Population and Development Review, vol. 6, no. 2, pp. 225-255, 1980.

[43] P. M. Eloundou-Enyegue, "Fertility and education: what do we now know?" in Commission on Behavioral and Social Sciences and Education (CBASSE '99), Critical Perspectives on Schooling and Fertility in the Developing World, 1999.

[44] A. J. Gage, "Women's socioeconomic position and contraceptive behavior in Togo," Studies in Family Planning, vol. 26, no. 5, pp. 264-277, 1995.

[45] D. Balk, "Individual and community aspects of women's status and fertility in rural Bangladesh," Population Studies, vol. 48, no. 1, pp. 21-45, 1994.

[46] M. M. Kritz, P. Makinwa-Adebusoye, and D. T. Gurak, "Wife's Empowerment and Fertility in Nigeria: The Role of Context," Cornell University Population and Development Program Working Paper Series no. 97.05, 1997.

[47] A. Pebley and W. Mbugua, "Polygyny and fertility in SubSaharan Africa," in Reproduction and Social Organization in Sub-Saharan Africa, R. J. Lesthaeghe, Ed., pp. 338-364, University of California Press, Berkeley, Calif, USA, 1989. 
[48] P. M. Eloundou-Enyegue and A. E. Calvès, "Till marriage do us part: education and remittances from married women in Africa," Comparative Education Review, vol. 50, no. 1, pp. 1-20, 2006.

[49] NPC, "National policy on population and sustainable development," in National Population Commission, Government of Nigeria, Abuja, Nigeria, 2004.

[50] V. E. Okon, Origins of Ruwan Dare, edited by S. W. Connolly, Population Media Center, Kano, Nigeria, 2011.

[51] M. M. Kritz and P. Makinwa-Adebusoye, "Couple agreement on wife's autonomy and reproductive dynamics in Nigeria," in Proceedings of the IUSSP 24th General Population Conference, Salvador, Brazil, August 2001.

[52] S. R. Schuler and S. M. Hashemi, "Credit programs, women's empowerment, and contraceptive use in rural Bangladesh," Studies in Family Planning, vol. 25, no. 2, pp. 65-76, 1994.

[53] A. Bandura, Social Foundations of Thought and Action: A Social Cognitive Theory, Prentice Hall, Englewood Cliffs, NJ, USA, 1986.

[54] W. N. Ryerson, The Effectiveness of Entertainment Mass Media in Changing Behavior, Population Media Center, Shelburne, Canada, 2010.

[55] T. D. Cook and D. T. Campbell, Quasi-Experimentation: Design and Analysis for Field Settings, Rand McNally, Chicago, Ill, USA, 1979. 

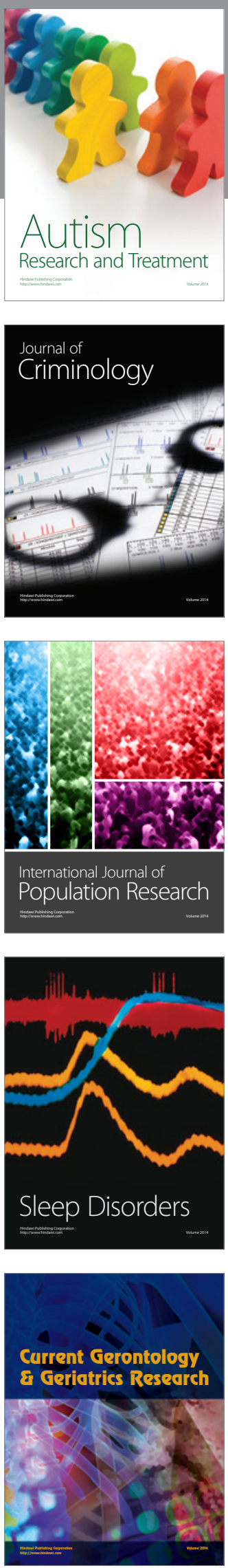


Submit your manuscripts at

http://www.hindawi.com
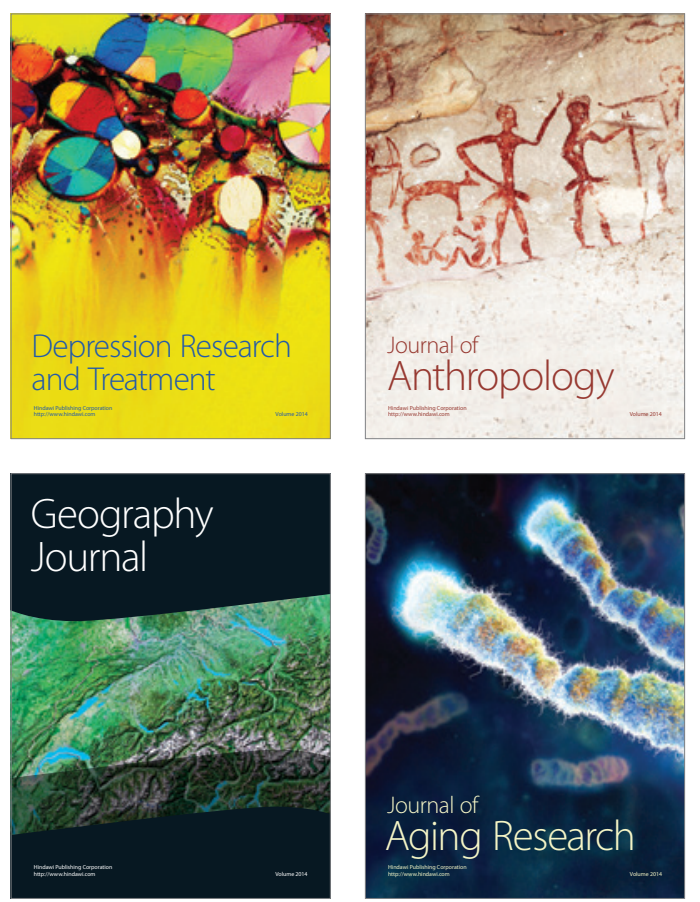
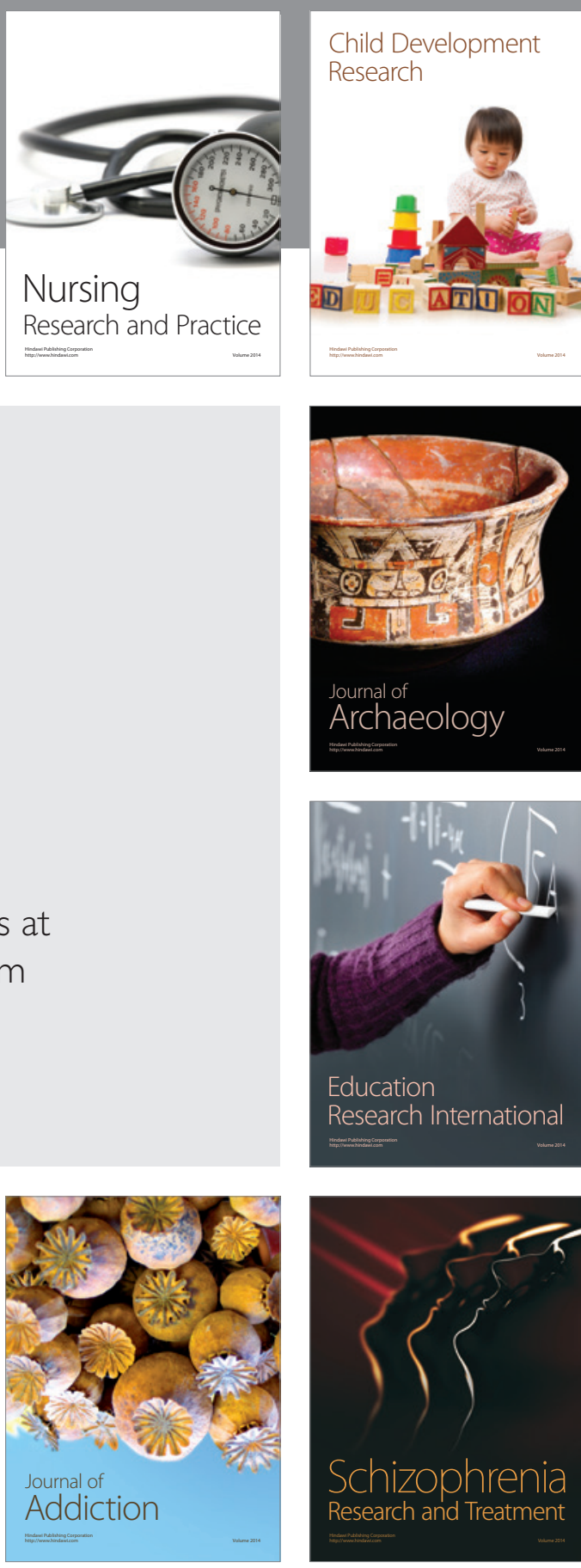

(D)
